\title{
What Is the Source of Occupational Stress and Burnout?
}

\section{Michael Galanakis, Evangelia Alexandri, Kalliopi Kika, Xristofili Lelekanou, Margarita Papantonopoulou, Dimitra Stougiannou, Melina Tzani}

Neapolis University of Pafos, Pafos, Cyprus

Email: galanakismichael@hotmail.com

How to cite this paper: Galanakis, M., Alexandri, E., Kika, K., Lelekanou, X., Papantonopoulou, M., Stougiannou, D., \& Tzani, M. (2020). What Is the Source of Occupational Stress and Burnout? Psychology, $11,647-662$.

https://doi.org/10.4236/psych.2020.115044

Received: April 3, 2020

Accepted: May 11, 2020

Published: May 14, 2020

Copyright $\odot 2020$ by author(s) and Scientific Research Publishing Inc. This work is licensed under the Creative Commons Attribution International License (CC BY 4.0).

http://creativecommons.org/licenses/by/4.0/

\section{(c) (i) Open Access}

\begin{abstract}
The purpose of this research was to examine the differences between the two genders in terms of occupational stress and burnout, as well as the effect of years of service on 141 Primary Education teachers. The degree of correlation between stress and burnout was also examined. A demographic questionnaire, teachers' emotional stress questionnaire and teachers' burnout questionnaire were used for data collection. The results of the study showed that there were no differences between men and women in terms of work stress and burnout. It has also been shown that years of service do not affect the degree of stress and burnout experienced by teachers and are not associated with feelings of exhaustion, depersonalisation, and personal achievement. However, according to the correlation analysis, a statistically significant relationship between work stress and occupational burnout was observed. The findings of this study are in agreement with relevant studies and can be used for early recognition and more effective occupational coping and treatment.
\end{abstract}

\section{Keywords}

Burnout, Work Stress, Primary School Teachers, Greece, Strain, Stressors

\section{Introduction}

Stress that develops in the workplace has been the subject of many studies as it directly affects the physical and mental health of employees (Elahi \& Apoorva, 2012). In some cases, the effects of stress take on a social problem dimension with serious consequences at both the individual and socio-economic level (Mouzoura, 2005).

In particular, teachers are called upon daily to cope with difficult conditions 
and challenges both in their workplace and in their interpersonal work relations (colleagues, students, management) that have been exacerbated in recent years (O'Donell \& Wang, 2009). The long-term volatility of occupational rehabilitation coupled with the financial crisis of recent years in Greece has resulted in stress and occupational burnout in the teaching staff that is affecting its efficiency, creating emotional and mental exhaustion (Maslach, 2003).

There are many factors responsible for teachers' work stress, according to international literature. However, the few studies done in Primary Education make it necessary to carry out this research. Identifying teachers' subjective perceptions of the factors responsible for stress and recording it will be crucial for better coping (Coxetal, 2000; La Montagneetal, 2007). Also investigating occupational stress and its symptoms is in line with World Health Organization guidelines that pinpoint stress as a serious health hazard in all countries.

\section{Teachers' work stress}

The definition of teacher stress that is prevalent is that of Kyriacou and Sutcliffe (1977). According to this definition, teacher stress is directly related to their perception that their work situation has an impact on their self-esteem. Stress is therefore defined as the emergence of various negative emotions that are the result of many different roles of the teacher.

The issue of teacher stress has been a concern for many researchers abroad as well as in Greece. In her research, Collie (2010) examined the relationship between educational stress and school climate through questionnaires completed online. Based on the results, a positive school climate leads to a reduction in educational stress.

It was also examined whether there is a difference in levels of educational stress between countries with different social and economic backgrounds. Research by Eres and Atanasoka (2011) on Turkey and Northern Macedonia showed that teachers in the second country were more stressed mainly due to the constant changes in their working conditions. In Greece teachers' stress has been seriously underdiagnosed and little has been done in terms of coping, provision and therapy. Mostly Greek Teachers suffer from the lack of resources accompanied by long working hours and exhausting working demands. Also Stress in Greek Teachers has been associated with productivity decrease, deteriorating interpersonal relationships among colleagues, a lack of job ownership and dedication and serious health problems like heart attacks, cancer, strokes to name a few.

Certain factors seem to play a vast role in the stress phenomenon in Greek teachers like gender, occupational status and form of occupational relationship, public or private sector environment, age and previous psychopathology. Also there seems to be a relationship between stress levels and burnout levels as well as between stress levels and depression. Finally some key variables like years of service, salary, performance evaluation, socio-demographic synthesis of the classroom, relationship with the parents and other teachers have not yet been examined to a satisfactory degree. 


\section{Occupational burnout}

The term psychological exhaustion, also known as burn-out in international literature, was first used in 1960 by experts to describe the effects of chronic use of addictive substances on the body. Occupational burnout syndrome was, however, emerged by clinical psychologist Herbert Freundenberger (1974) describing it as a state of mental and physical fatigue, as a result of the disavowal of expectations with regard to the expected reward of offering and devotion to a purpose.

The most widespread definition refers to occupational burnout as a syndrome of occupational exhaustion, depersonalization, and diminished personal achievement that happens mainly to people working in the field of service provision (Maslach \& Jackson, 1986).

Teacher burnout is defined as physical, emotional and psychological exhaustion, which begins when the teacher is possessed by a feeling of loss of interest in teaching. Occupational burnout syndrome is the direct result of a prolonged exposure to stressful working conditions. In professional groups such as teachers, there is a higher risk of the syndrome, as the teacher's profession is anthropocentric, the workplace has an emotional dimension and is characterised by high responsibilities, intense stressful situations, little control over decision making and educational policy, as well as little or no positive feedback (Antoniou \& Dallas, 2010).

Teacher burnout syndrome has occasionally been the subject of research both in Greece and abroad, with studies referring to teachers predominating compared to those of other professionals focused on services with humans at their centre. Many studies have largely investigated the causes of professional burnout in relation to teacher characteristics (personality, demographic factors), as well as work and work environment characteristics. Concerning the relation of the burnout syndrome to factors such as age and teaching experience of the teachers, gender and marital status, the results are quite contradictory. In Greece, similar studies have shown that teacher burnout levels are low to moderate compared to other countries while secondary education teachers have reported more burnout than primary education teachers (Antoniou \& Dalla, 2010; Charalampous, 2012; Tsigilis, Zournatzi, \& Koustelios, 2011; Vassilopoulos, 2012). The main research models that have prevailed worldwide for interpreting occupational burnout are the interactive model of Cherniss (1980), the model of Edelwich and Brodsky (1980), the three-dimensional model of Maslach and Jackson (1981), and the model of Pines and Aronson (1988). In recent years, two more models are of interest, the Copenhagen model (Kristensen et al, 2005) and Shirom and Ezrachi (2003) introducing the term "cognitive impairment".

\section{Purpose of the research and research questions}

The purpose of this study was to examine the phenomenon of work stress and occupational burnout of primary school teachers in Greece focusing on two factors that have been shown to play an important role in the development of these syndromes. The research questions that have been posed are: 
1) Is there a difference between the two genders in the occurrence and intensity of work stress and occupational burnout?

2) To what extent years of service play a role in the occurrence of this syndrome?

3) What is the relationship between stress and burnout, that is, too much stress leading to burnout and vice versa?

The results of the research aim to provide important information in the field of education for the purpose of creating support programs for teachers who have to deal with stress at school and show signs of educational burnout.

We strongly believe that teachers are the backbone of society and their role to stability, progress and civilization is crucial. Moreover they function in a profession somewhat inadequately paid while their daily strains are high. It is important to show what the stress levels in teachers are in the new era as well as to provoke government provision and care in order to facilitate their goals and secure occupational health. Also the investigating of teachers stress and the factors that lead to its increase can serve as a benchmark regarding coping strategies that are utilized at the moment as well as new studies that are going to be fulfilled in the future.

\section{Research Hypotheses:}

H01: gender does not affect the level of stress experienced by primary school teachers.

H1: gender affects the level of stress experienced by primary school teachers.

H02: gender does not affect the occurrence of occupational burnout in primary education teachers.

$\mathrm{H} 2$ : gender affects the occurrence of occupational burnout in primary education teachers.

H03: years of service do not affect the degree of stress experienced by primary education teachers.

H3: years of service affect the degree of stress experienced by primary education teachers.

H04: years of service do not affect the occurrence of occupational burnout in primary education teachers.

H4: years of service affect the occurrence of occupational burnout in primary education teachers.

H05: There is no correlation between stress and burnout in the sample teachers.

H5: There is a positive correlation between stress and burnout in the sample teachers.

\section{Method}

\section{Sample}

In this study, the participants were teachers employed in Primary schools and therefore teachers from other grades were excluded as the research questions were intended to examine the stress and degree of professional burnout expe- 
rienced by primary education teachers. All teachers were included regardless of gender, age, background, level of education and specialty. To ensure statistical power and significance of the results, 141 teachers participated in the study.

\section{Tools}

The research was quantitative, with the use of questionnaires. It was also cross-sectional. Questionnaires were administered and answered by teachers. The research sample was a convenience sample. The questionnaires were distributed manually to known fellow teachers of the researchers and some were also sent to participants electronically via email.

A demographic variables questionnaire, teachers' emotional stress questionnaire and teacher burnout questionnaire were used for conducting the research.

\section{Demographic questionnaire}

The demographic questionnaire was compiled by our team to record information on gender, age, marital status, specialty, educational level and years of service in education.

\section{Questionnaire for recording sources of emotional intensity of teachers}

The Sources of Emotional Intensity Questionnaire for Teachers was used to identify the factors that cause work stress on teachers. This questionnaire was developed by Mouzoura (2005) and based on the specific characteristics of the sample; some modifications were made to it by Mparis (2018). It is largely based on the questionnaires of Hui \& Chan (1996), Kyriacou \& Satcliffe (1978b) and Okebukola \& Jegede (1989). It consists of 41 closed-ended questions with answers on a 5 -point Likert scale ranging from $1=$ no stress to $5=$ too much stress. The participant answers whether he or she is satisfied with the content of the items. The tool has undergone internal consistency testing and has an excellent reliability index (Cronbach $\alpha=0.90$ ).

\section{Questionnaire for the evaluation of teacher burnout}

The second research tool used is Maslach \& Jackson's (1986) “Maslach Burnout Inventory-MBI" and more specifically the modified version of the questionnaire (MBI-ES, 1996) that has been adapted to target teachers. The translation and adaptation of the questionnaire into Greek was done by Kokkinos (2006). The purpose of the questionnaire is to record the components of occupational burnout on an emotional, behavioural and cognitive level. It includes 22 items that measure three dimensions of occupational burnout, namely emotional exhaustion, depersonalisation and lack of personal achievement. Participants were asked to rate the frequency with which a condition occurs, using a 7-point Likert-type scale ranging from 1 (never occurs) to 7 (occurs every day). High scores on the Scales of Emotional Exhaustion and Depersonalisation are considered to indicate high levels of occupational burnout. In contrast, low scores on the Personal Achievement scale are considered to indicate a high degree of burnout. The questionnaire has been tested for its validity in the Greek population as well as its reliability.

Ethics and code of conduct

Matters of ethics and code of conduct are an integral part of scientific research 
from conception, realisation to completion through publication of results. The researchers were obliged to inform the participants fully about the purpose, aims and use of the results of the research through the information and consent form. The research was voluntary, so there was the choice of whether or not to participate and the option of leaving at any time without impact. In addition, it was emphasised that participation in the process poses no risk (Robson, 2011). Another issue was the protection of personal data and the safeguarding thereof by respecting the anonymity of the participants, so there was a codification of the questionnaires. Finally, the resulting data and results were not altered, were honest and available to the participants.

\section{Results}

Statistical analysis and processing of the data obtained from the completed questionnaires was done with SPSS Statistics v.25. Independent measurements T-test was used to determine the relationship between gender and stress. For the relationship between stress and previous service ANOVA-analysis was performed, since previous service was measured by ordinal categories. T-test was performed for the relationship between gender and occupational burnout. For the relationship between previous service and burnout, ANOVA-analysis was performed, as each subscale of burnout, namely Exhaustion, Personal Achievements, and Depersonalisation and its total score had to be measured. It was also investigated whether tenure influences the degree of stress experienced by teachers by correlational analysis.

The duration of the investigation was set from November 2019 to January 2020, namely:

\begin{tabular}{cc}
\hline November 2019 & Distribution and collection of completed questionnaires \\
December 2019 & Statistical analysis of data \\
January 2020 & Report results \\
\hline
\end{tabular}

Regarding the first research question on whether there is a difference between the two genders in terms of work stress and occupational burnout, both the null hypothesis and the alternative were identified and then analyzed by the t-test method. The results are depicted below.

Table 1(a) lists the averages and standard deviations of the dependent variable stress of the two teacher groups (men and women).

In Table 1 (b) according to Levene's test, sig $>0.05$ which indicates that we have equal distributions.

From the results obtained, it appears that $\mathrm{t}(139)=-0.249, p>0.05$, indicating that the difference between them is not statistically significant. Therefore, we accept the null hypothesis that gender does not affect the occurrence of work stress among primary school teachers.

Regarding the second research question on whether there is a gender difference in the occurrence of occupational burnout, both the null hypothesis and the 
Table 1. (a) Mean and standard deviation of stress in men and women in our sample; (b) T-test analysis for the effect of gender on stress levels.

(a)

\begin{tabular}{cccccc}
\hline & sex & N & Mean & Std. Deviation & Std. Error Mean \\
\hline \multirow{2}{*}{ Stresstotal } & male & 43 & 129.047 & 23.249 & 3.545 \\
& female & 98 & 130.184 & 25.673 & 2.593 \\
\hline
\end{tabular}

(b)

\begin{tabular}{|c|c|c|c|c|c|c|c|c|c|c|}
\hline & \multirow[t]{2}{*}{$\begin{array}{l}\text { Levene's Test for } \\
\text { Equality of Variances }\end{array}$} & & & \multicolumn{5}{|c|}{ T-test for Equality of Means } & \multicolumn{2}{|c|}{$\begin{array}{l}\text { 95\% Confidence } \\
\text { Interval of the } \\
\text { Difference }\end{array}$} \\
\hline & & $\mathrm{F}$ & Sig. & t. & df. & $\begin{array}{c}\text { Sig. } \\
(2 \text {-tailed) }\end{array}$ & $\begin{array}{c}\text { Mean } \\
\text { Difference }\end{array}$ & $\begin{array}{l}\text { Std. Error } \\
\text { Difference }\end{array}$ & Lower & Upper \\
\hline \multirow[t]{2}{*}{ Stresstotal } & Equal variances assumed & 0.368 & 0.545 & -0.249 & 139 & 0.804 & -1.137 & 4.567 & -10.166 & 7.892 \\
\hline & Equal variances not assumed & & & -0.259 & 88.052 & 0.796 & -1.137 & 4.392 & -9.867 & 7.592 \\
\hline
\end{tabular}

alternative were examined and then analyzed by the t-test, which showed the following.

Table 2(a) lists the means and standard deviations of the dependent variable burnout of the two groups (men and women).

In Table 2(b) according to Levene's test, sig $=0.05$ which indicates that we do not have equal distributions and therefore take into account the second line of the table, where $\mathrm{t}(64.05)=-0.143, p>0.05$, which indicates that the difference between them is not statistically significant. Therefore, we accept the null hypothesis that gender does not affect the occurrence of occupational burnout in primary education teachers.

As to the third research question, about whether there is a relationship between stress and occupational burnout, that is to say, whether stress leads to occupational burnout or vice versa, both the null hypothesis and the alternative were identified and subsequently a correlational analysis was performed and showed the following:

Table 3(a) lists the means and standard deviations of the values of the two variables (stress and burnout).

Table 3(b) shows that the correlation between stress and burnout is $r=0.20$ and $p=0.01$, so we have a statistically significant correlation and accept the alternative assumption that work stress is correlated to occupational burnout.

As to the fourth research question on whether there is a relationship between years of service and stress, both the null and alternative hypotheses were examined and then Anova analysis was performed and showed the following:

A Test of Normality was initially conducted for normal distribution of the sample.

Based on the values in Table 4 (Sig. $=0.713$ ) the distribution from which the sample is derived is normal and thus we can proceed with the Anova.

When controlling for distributions based on Levene's Test, as shown in Table 5 , there is homogeneity between groups $(p>0.05)$ and thus the null hypothesis 
Table 2. (a) Mean and standard deviation of burnout in male and female teachers; (b) T-test analysis on the effect of gender on burnout.

(a)

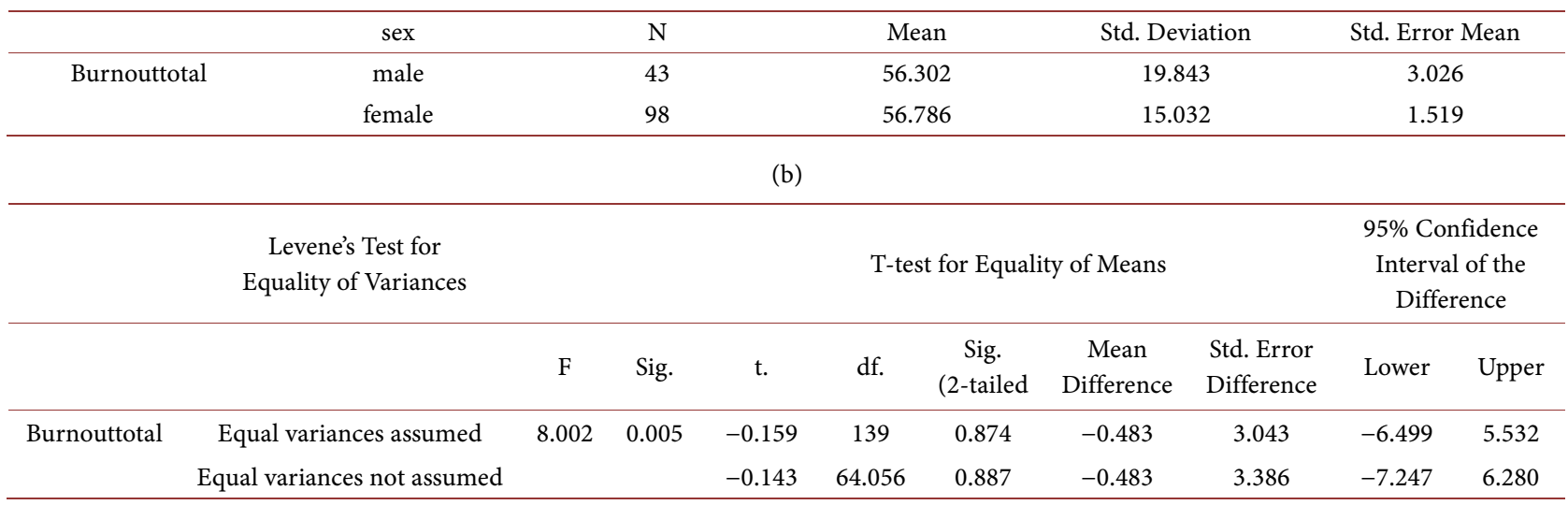

Table 3. (a) Descriptive statistics regarding stress and burnout levels in the sample; (b) Correlation analysis between stress and burnout.

(a)

\begin{tabular}{cccc}
\hline & Mean & Std. Deviation & N \\
\hline Stresstotal & 129.837 & 24.881 & 141 \\
Burnouttotal & 56.638 & 16.575 & 141 \\
\hline
\end{tabular}

(b)

\begin{tabular}{cccc}
\hline & & Stresstotal & Burnouttotal \\
\hline Stresstotal & Pearson Correlation & 1 & $0.197^{\star *}$ \\
& Sig. (1-tailed) & & 0.010 \\
& N & 141 & 141 \\
Burnouttotal & Pearson Correlation & $0.197^{\star *}$ & 1 \\
& Sig. (1-tailed) & 0.010 & 141 \\
\hline
\end{tabular}

${ }^{* *}$ Correlation is significant at the 0.01 level (1-tailed).

Table 4. Test of normality.

\begin{tabular}{cccccccc}
\hline & \multirow{2}{*}{$\begin{array}{l}\text { Years of } \\
\text { Service }\end{array}$} & \multicolumn{2}{c}{ Kolmogorov-Smirnov } & \multicolumn{3}{c}{ Shapiro-Wilk } \\
\cline { 2 - 7 } & Statistic & df & Sig. & Statistic & df & Sig. \\
\hline \multirow{3}{*}{ Stresstotal } & $1-10$ & 0.119 & 34 & $0.200^{*}$ & 0.978 & 34 & 0.713 \\
& $11-20$ & 0.080 & 63 & $0.200^{*}$ & 0.978 & 63 & 0.309 \\
& $21-30$ & 0.104 & 21 & $0.200^{*}$ & 0.955 & 21 & 0.429 \\
& $31-40$ & 0.118 & 23 & $0.200^{*}$ & 0.953 & 23 & 0.338 \\
\hline
\end{tabular}

Table 5. Distribution control.

\begin{tabular}{cccccc}
\hline & & Levene Statistic & df1 & df2 & Sig. \\
\hline \multirow{3}{*}{ Stresstotal } & Based on Mean & 1.185 & 3 & 137 & 0.318 \\
& Based on Median & 1.002 & 3 & 137 & 0.394 \\
& Based on Median and with adjusted df & 1.002 & 3 & 129.806 & 0.394 \\
& Based on trimmed mean & 1.102 & 3 & 137 & 0.351 \\
\hline
\end{tabular}


of equal distributions is not rejected.

Concerning the results of Anova in Table 6, it seems that there was no significant effect of prior service on stress levels, $\mathrm{F}(3,137)=1.352, p=0.260$. Therefore, the Null hypothesisis confirmed that years of service do not affect the degree of stress experienced by primary education teachers.

When checking multiple comparisons (Table 7) no statistically significant difference was observed between the individual levels of service $(p>0.05)$.

Concerning the fifth research question as to whether the years of service of Primary Education teachers play a role in the emergence of occupational burnout syndrome as a whole and in each of its subscales that is, emotional exhaustion, depersonalisation and personal achievement. Both the null hypothesis and the alternative hypothesis were examined and normality testing was initially performed to check if there is a normal distribution of the sample across each group of years of service.

As shown by the results in Table 8 . Because the values of sig. are greater than $\mathrm{a}=0.05$, which is usually defined as a level of statistical significance, and the null hypothesis cannot be rejected, we assume that the distribution is normal. The discrepancy in group $11-20$ is considered not to affect the regularity of the sample distribution.

Table 6. ANOVA between years of experience and stress levels stress total.

\begin{tabular}{cccccc}
\hline & Sum of Squares & df & Mean Square & F & Sig. \\
\hline Between Groups & 2492.030 & 3 & 830.677 & 1.352 & 0.260 \\
Within Groups & $84,181.218$ & 137 & 614.461 & & \\
Total & $86,673.248$ & 140 & & & \\
\hline
\end{tabular}

Table 7. Multiple comparisons dependent variable: Stress total Tukey HSD.

\begin{tabular}{|c|c|c|c|c|c|}
\hline $\begin{array}{c}\text { (I) } \\
\text { years of } \\
\text { service }\end{array}$ & $\begin{array}{c}(\mathrm{J}) \\
\text { years of } \\
\text { service }\end{array}$ & $\begin{array}{c}\text { Mean } \\
\text { Difference } \\
(\mathrm{I}-\mathrm{J})\end{array}$ & $\begin{array}{l}\text { Std. } \\
\text { Error }\end{array}$ & Sig. & $\begin{array}{c}95 \% \text { Confidence Interval } \\
\text { Lower Bound }\end{array}$ \\
\hline \multirow{3}{*}{$1-10$} & $11-20$ & -5.123 & 5.275 & 0.766 & -18.843 \\
\hline & $21-30$ & -13.647 & 6.880 & 0.199 & -31.541 \\
\hline & $31-40$ & -7.125 & 6.692 & 0.712 & -24.531 \\
\hline \multirow{3}{*}{$11-20$} & $1-10$ & 5.123 & 5.275 & 0.766 & -8.596 \\
\hline & $21-30$ & -8.524 & 6.246 & 0.524 & -24.769 \\
\hline & $31-40$ & -2.002 & 6.039 & 0.987 & -17.709 \\
\hline \multirow{3}{*}{$21-30$} & $1-10$ & 13.647 & 6.880 & 0.199 & -4.246 \\
\hline & $11-20$ & 8.524 & 6.246 & 0.524 & -7.721 \\
\hline & $31-40$ & 6.522 & 7.482 & 0.819 & -12.937 \\
\hline \multirow{3}{*}{$31-40$} & $1-10$ & 7.125 & 6.692 & 0.712 & -10.281 \\
\hline & $11-20$ & 2.002 & 6.039 & 0.987 & -13.704 \\
\hline & $21-30$ & -6.522 & 7.482 & 0.819 & -25.981 \\
\hline
\end{tabular}


It was also checked for any fluctuations as a one-way anova control condition. As shown in the following Levene table, sig $>0.05$ which indicates that we have equal variances, since we cannot reject the null hypothesis of equality of variances (Table 9).

Analysis of variance (Anova) was then followed to answer the research question of whether years of service play a role in the emergence of occupational burnout syndrome in primary school teachers. The results of Anova are presented in Table 10.

From the results obtained, it appears that sig. $>0.05$ in all groups, indicating that the difference between them is not statistically significant. Therefore, we accept the null hypothesis H0, that is to say, that teachers' burnout levels are not affected by their years of service.

In addition, a Tukey test was performed to compare the relationship of each service group with the others separately. The results are presented in Table 11.

As shown in the multiple comparisons test, no statistically significant difference between the groups was observed.

Finally, Anova was tested for each of the subscales of occupational burnout, namely emotional exhaustion, depersonalisation, and personal achievement, as well as multiple comparisons for each subscale. As can be seen in the tables below, there is no statistically significant difference for any of the scales of occupational burnout, so in these cases we accept the null hypothesis $\mathrm{H} 0$, that is, teachers' years of service do not affect their emotional exhaustion, nor the feeling of depersonalisation, or the personal achievement (Tables 12-20).

Table 8. Test of normality.

\begin{tabular}{ccccccc}
\hline \multirow{2}{*}{$\begin{array}{c}\text { years of } \\
\text { service }\end{array}$} & \multicolumn{3}{c}{ Kolmogorov-Smirnov $^{*}$} & \multicolumn{3}{c}{ Shapiro-Wilk $^{2}$} \\
\cline { 2 - 7 } & Statistic & $\mathrm{df}$ & Sig. & Statistic & df & Sig. \\
\hline $1-10$ & 0.088 & 34 & $0.200^{*}$ & 0.976 & 34 & 0.634 \\
$11-20$ & 0.158 & 63 & 0.000 & 0.934 & 63 & 0.002 \\
$21-30$ & 0.112 & 21 & $0.200^{*}$ & 0.946 & 21 & 0.287 \\
$31-40$ & 0.098 & 23 & $0.200^{*}$ & 0.955 & 23 & 0.362 \\
\hline
\end{tabular}

Table 9. Levene test of equal variances burnout total.

\begin{tabular}{cccc}
\hline Levene Statistic & df1 & df2 & Sig. \\
\hline 0.492 & 3 & 137 & 0.689 \\
\hline
\end{tabular}

Table 10. ANOVA regarding the effect of years of experience on burnout levels burnout total.

\begin{tabular}{cccccc}
\hline & Sum of Squares & df & Mean Square & F & Sig. \\
\hline Between Groups & 1034.790 & 3 & 344.930 & 1.263 & 0.290 \\
Within Groups & $37,427.763$ & 137 & 273.195 & & \\
Total & $38,462.553$ & 140 & & & \\
\hline
\end{tabular}


Table 11. Post hoc analysis on the effect of years of experience on burnout dependent variable: Burnout total Tukey HSD.

\begin{tabular}{|c|c|c|c|c|c|c|}
\hline \multirow{2}{*}{$\begin{array}{l}\text { (I) years of } \\
\text { service }\end{array}$} & \multirow{2}{*}{$\begin{array}{l}\text { (J) years of } \\
\text { service }\end{array}$} & \multirow{2}{*}{$\begin{array}{c}\text { Mean } \\
\text { Difference } \\
(\mathrm{I}-\mathrm{J})\end{array}$} & \multirow{2}{*}{$\begin{array}{l}\text { Std. } \\
\text { Error }\end{array}$} & \multirow{2}{*}{ Sig. } & \multicolumn{2}{|c|}{ 95\% Confidence Interval } \\
\hline & & & & & Lower Bound & Upper Bound \\
\hline \multirow{3}{*}{$1-10$} & $11-20$ & -0.100 & 3.517 & 1.000 & -9.248 & 9.047 \\
\hline & $21-30$ & 3.455 & 4.587 & 0.875 & -8.476 & 15.386 \\
\hline & $31-40$ & 7.090 & 4.462 & 0.388 & -4.515 & 18.696 \\
\hline \multirow{3}{*}{$11-20$} & $1-10$ & 0.100 & 3.517 & 1.000 & -9.047 & 9.248 \\
\hline & $21-30$ & 3.555 & 4.164 & 0.829 & -7.276 & 14.387 \\
\hline & $31-40$ & 7.191 & 4.026 & 0.285 & -3.281 & 17.664 \\
\hline \multirow{3}{*}{$21-30$} & $1-10$ & -3.455 & 4.587 & 0.875 & -15.386 & 8.476 \\
\hline & $11-20$ & -3.555 & 4.164 & 0.829 & -14.387 & 7.276 \\
\hline & $31-40$ & 3.635 & 4.988 & 0.885 & -9.339 & 16.610 \\
\hline \multirow{3}{*}{$31-40$} & $1-10$ & -7.090 & 4.462 & 0.388 & -18.696 & 4.515 \\
\hline & $11-20$ & -7.191 & 4.026 & 0.285 & -17.664 & 3.281 \\
\hline & $21-30$ & -3.635 & 4.988 & 0.885 & -16.610 & 9.339 \\
\hline
\end{tabular}

Table 12. Levene test of equal variances exhaustion.

\begin{tabular}{cccc}
\hline Levene Statistic & df1 & df2 & Sig. \\
\hline 0.206 & 3 & 137 & 0.892 \\
\hline
\end{tabular}

Table 13. ANOVA of the effect of tenure on emotional exhaustion, depersonalization and lack of achievement exhaustion.

\begin{tabular}{cccccc}
\hline & Sum of Squares & df & Mean Square & F & Sig. \\
\hline Between Groups & 154.029 & 3 & 51.343 & 0.430 & 0.732 \\
Within Groups & $16,374.113$ & 137 & 119.519 & & \\
Total & $16,528.142$ & 140 & & & \\
\hline
\end{tabular}

Table 14. Post hoc analysis dependent variable: Emotional exhaustion Tukey HSD.

\begin{tabular}{|c|c|c|c|c|c|c|}
\hline \multirow{2}{*}{$\begin{array}{l}\text { (I)years of } \\
\text { service }\end{array}$} & \multirow{2}{*}{$\begin{array}{l}(\mathrm{J}) \text { years of } \\
\text { service }\end{array}$} & \multirow{2}{*}{$\begin{array}{c}\text { Mean } \\
\text { Difference } \\
(\mathrm{I}-\mathrm{J})\end{array}$} & \multirow{2}{*}{$\begin{array}{l}\text { Std. } \\
\text { Error }\end{array}$} & \multirow{2}{*}{ Sig. } & \multicolumn{2}{|c|}{ 95\% Confidence Interval } \\
\hline & & & & & Lower Bound & Upper Bound \\
\hline \multirow{3}{*}{$1-10$} & $11-20$ & -1.499 & 2.326 & 0.917 & -7.549 & 4.551 \\
\hline & $21-30$ & -0.387 & 3.034 & 0.999 & -8.279 & 7.503 \\
\hline & $31-40$ & 1.392 & 2.951 & 0.965 & -6.284 & 9.069 \\
\hline \multirow{3}{*}{$11-20$} & $1-10$ & 1.499 & 2.326 & 0.917 & -4.551 & 7.549 \\
\hline & $21-30$ & 1.111 & 2.754 & 0.978 & -6.053 & 8.275 \\
\hline & $31-40$ & 2.891 & 2.663 & 0.699 & -4.035 & 9.818 \\
\hline \multirow{3}{*}{$21-30$} & $1-10$ & 0.387 & 3.034 & 0.999 & -7.503 & 8.279 \\
\hline & $11-20$ & -1.111 & 2.754 & 0.978 & -8.275 & 6.053 \\
\hline & $31-40$ & 1.780 & 3.299 & 0.949 & -6.801 & 10.362 \\
\hline \multirow{3}{*}{$31-40$} & $1-10$ & -1.392 & 2.951 & 0.965 & -9.069 & 6.284 \\
\hline & $11-20$ & -2.891 & 2.663 & 0.699 & -9.818 & 4.035 \\
\hline & $21-30$ & -1.780 & 3.299 & 0.949 & -10.362 & 6.801 \\
\hline
\end{tabular}


Table 15. Levene test of equal variances depersonalization.

\begin{tabular}{cccc}
\hline Levene Statistic & df1 & df2 & Sig. \\
\hline 2033 & 3 & 137 & 0.112 \\
\hline
\end{tabular}

Table 16. ANOVA on the effect of tenure on depersonalization.

\begin{tabular}{cccccc}
\hline Depersonalization & Sum of Squares & $\mathrm{df}$ & Mean Square & $\mathrm{F}$ & Sig. \\
\hline Between Groups & 95.694 & 3 & 31.898 & 2.582 & 0.056 \\
Within Groups & 1692.490 & 137 & 12.354 & & \\
Total & 1788.184 & 140 & & & \\
\hline
\end{tabular}

Table 17. Post hoc analysis dependent variable: Depersonalisation Tukey HSD.

\begin{tabular}{ccccccc}
\hline \multirow{2}{*}{$\begin{array}{c}\text { (I) years of } \\
\text { service }\end{array}$} & $\begin{array}{c}\text { (J) years of } \\
\text { service }\end{array}$ & $\begin{array}{c}\text { Mean } \\
\text { Difference }\end{array}$ & $\begin{array}{c}\text { Std. } \\
\text { (I-J) }\end{array}$ & Error & Sig. & \multicolumn{2}{c}{$95 \%$ Confidence Interval } \\
\cline { 6 - 7 } & $11-20$ & 0.225 & 0.747 & 0.990 & -1.719 & 2.170 \\
\hline \multirow{2}{*}{$1-10$} & $21-30$ & 1.368 & 0.975 & 0.500 & -1.168 & 3.905 \\
& $31-40$ & 2.254 & 0.948 & 0.087 & -0.213 & 4.722 \\
& $1-10$ & -0.225 & 0.747 & 0.990 & -2.170 & 1.719 \\
$11-20$ & $21-30$ & 1.142 & 0.885 & 0.571 & -1.160 & 3.446 \\
& $31-40$ & 2.028 & 0.856 & 0.088 & -0.198 & 4.256 \\
& $1-10$ & -1.368 & 0.975 & 0.500 & -3.905 & 1.168 \\
$21-30$ & $11-20$ & -1.142 & 0.885 & 0.571 & -3.446 & 1.160 \\
& $31-40$ & 0.886 & 1.060 & 0.838 & -1.873 & 3.645 \\
& $1-10$ & -2.254 & 0.948 & 0.087 & -4.722 & 0.213 \\
& $11-20$ & -2.028 & 0.856 & 0.088 & -4.256 & 0.198 \\
& $21-30$ & -0.886 & 1.060 & 0.838 & -3.645 & 1.873 \\
\hline
\end{tabular}

Table 18. Leven test of equal variances personal achievement.

\begin{tabular}{cccc}
\hline Levene Statistic & $\mathrm{df1}$ & $\mathrm{df2}$ & Sig. \\
\hline 0.237 & 3 & 137 & 0.870 \\
\hline
\end{tabular}

Table 19. ANOVA on the effect of tenure on personal achievement personal achievement.

\begin{tabular}{cccccc}
\hline & Sum of Squares & df & Mean Square & F & Sig. \\
\hline Between Groups & 189.787 & 3 & 63.262 & 1.284 & 0.283 \\
Within Groups & 6751.461 & 137 & 49.281 & & \\
Total & 6941.248 & 140 & & & \\
\hline
\end{tabular}

Table 20. Post hoc analysis dependent variable: personal achievement Turkey HSD.

\begin{tabular}{ccccccc}
\hline $\begin{array}{c}\text { (I) years of } \\
\text { service }\end{array}$ & $\begin{array}{c}\text { (J) years of } \\
\text { service }\end{array}$ & $\begin{array}{c}\text { Mean } \\
\text { Difference } \\
(\mathrm{I}-\mathrm{J})\end{array}$ & $\begin{array}{c}\text { Std. } \\
\text { Error }\end{array}$ & Sig. & & \multicolumn{2}{c}{ 95\% Confidence Interval } \\
\cline { 5 - 6 } & $11-20$ & 1.173 & 1.493 & 0.861 & -2.712 & 5.058 \\
$1-10$ & $21-30$ & 2.474 & 1.948 & 0.583 & -2.592 & 7.542 \\
& $31-40$ & 3.443 & 1.895 & 0.270 & -1.480 & 8.373 \\
\hline
\end{tabular}




\begin{tabular}{ccccccc} 
Continued & \multicolumn{7}{c}{} \\
\hline \multirow{3}{*}{$11-20$} & $1-10$ & -1.173 & 1.493 & 0.861 & -5.058 & 2.712 \\
& $21-30$ & 1.301 & 1.768 & 0.882 & -3.299 & 5.902 \\
& $31-40$ & 2.270 & 1.710 & 0.547 & -2.177 & 6.718 \\
& $1-10$ & -2.474 & 1.948 & 0.583 & -7.542 & 2.592 \\
$21-30$ & $11-20$ & -1.301 & 1.768 & 0.882 & -5.902 & 3.299 \\
& $31-40$ & 0.968 & 2.118 & 0.968 & -4.541 & 6.479 \\
& $1-10$ & -3.443 & 1.895 & 0.270 & -8.373 & 1.485 \\
& $11-20$ & -2.270 & 1.710 & 0.547 & -6.718 & 2.177 \\
& $21-30$ & -0.968 & 2.118 & 0.968 & -6.479 & 4.541 \\
\hline
\end{tabular}

\section{Discussion}

The purpose of this study was to examine the differences between the two genders in terms of occupational stress and burnout, as well as the effect of years of service on Primary Education teachers. It turned out that there were no differences between men and women in terms of work stress and burnout. Also, years of service did not appear to influence the degree of stress and burnout experienced by teachers. In particular, it has been observed that years of teaching experience are not associated with emotional exhaustion, a sense of depersonalisation and personal achievement of teachers. An important finding of the study is the existence of a statistically significant association between work stress and burnout, suggesting that work stress is related to burnout. These results are similar to findings from previous studies suggesting that in occupational groups, such as teachers, prolonged exposure to stressful working conditions contributes to experiencing emotional and psychological exhaustion (Antoniou \& Dalla, 2010).

This research is an additional effort to document the sources of anxiety and burnout in primary education teachers. Exploring sources of professional stress is needed in order to design training programs that will help teachers cope with the increasing demands of the school environment. The state could take into account the results of making changes to the education system for the benefit of Greek teachers. Higher education institutions should make good use of the findings to communicate the difficulties of the teaching profession to students in the pedagogical departments, as well as to prepare them appropriately through practical training.

The results of the study could be used for the design and application of certain stress coping interventions. For example stress coping should not be age related or tenure related. An equal number of young teachers with little or no experience, with those who are more mature and experienced, are also affected by stress and they should be aided by specific counseling programs in order to better cope with stress levels. Also since burnout is linked to occupational stress the school management should take drastic measures in order to provide hours for 
relaxation in the working shift as well as vacation and off days as an effort for de-buffering strain levels in teachers. Finally, as practical implications are concerned, the use of specialised experts in the direction of stress management as well as the obligational use of specific stress relief activities in all schools should be initiated immediately.

There are some limitations to conducting this research. Self-report questionnaires used as a method of data collection may not deal with the subject in depth and are often considered unreliable because participants want to present a positive image of themselves and may hurry to complete them. An additional limitation is that levels of work-related stress and burnout were measured over a specific period during the month November. No measurements were made during the school year where levels were likely to be elevated. Due to the short time frame of the survey, another limitation is the sample size which could be larger. The sample of the study was not representative of the population, as they were known to the research team and the majority of the participants were women. Participation of kindergarten teachers and teachers with other specialties was small. The research was conducted on teachers who teach in public schools in specific areas of Greece and therefore the results cannot be generalised to all teachers.

Proposed future surveys may include teachers from all parts of Greece to cover several geographical areas. This would help capture more views and result in a larger number of conclusions that would improve and address these problems. In the future, it may also be possible to conduct a survey of secondary education teachers in order to identify similarities and differences between different levels. In future research, it would be useful to have a larger and more balanced sample of the number of men and women involved in order to draw conclusions. Examining the levels of work stress and burnout at different times during the school year will give a more complete picture of the concepts under study. Other methods of data collection, such as semi-structured interview, observation, diary, could also be used at a later stage to determine if they end up with the same results as the questionnaires (Van Dick \& Wagner, 2001). The combination of qualitative and quantitative data collection methods can provide reliable information.

\section{Conflicts of Interest}

The authors declare no conflicts of interest regarding the publication of this paper.

\section{References}

Antoniou, A. S., \& Ntalla, M. (2010). Burnout and Job Satisfaction in Greek Primary and Secondary School Teachers. A Comparative Study. In C. Karakioulafi, \& M. Spiridaki (Eds.), Labour and Society (pp. 365-399). Athens: Dionikos.

Charalampous, E. (2012). Sources of Occupational Stress and Burnout in Primary School Teachers. Bachelor Thesis, Athens: Charokopeio University of Athens. 
Cherniss, C. (1980). Professional Burnout in Human Service Organizations. New York: Praeger.

Collie, R. I. (2010). Social and Emotional Learning and School Climate. Predictors of Teacher Stress, Job Satisfaction, and Sense of Efficacy. Thesis, Master of Arts in the Faculty of Graduate Studies (Human Development, Learning and Culture), Vancouver: The University of British Columbia.

Edelwich, J., \& Brodsky, A. (1980). Burnout: Stages of Disillusionment in the Helping Professions. Dordrecht: Kluwer Academic, Plenum Publishers.

Elahi, Y. A., \& Apoorva, M. (2012). A Detail Study on Length of Service and Role Stress of Banking Sector in Lucknow Region. Research Journal of Management Sciences, 1, 15-18.

Eres, F., \& Atanasoka, T. (2011). Occupational Stress of Teachers: A Comparative Study between Turkey and Macedonia. International Journal of Humanities and Social Science, 1, 59-65. https://doi.org/10.1111/j.1540-4560.1974.tb00706.x

Freundenberger, H. J. (1974). Staff Burnout. Journal of Social Issues, 30, 159-165.

Hui, E. P., \& Chan, D. (1996). Teachers Stress and Guidance Work in Hong Kong Secondary School Teachers. British Journal of Guidance and Counseling, 24, 199-211. https://doi.org/10.1080/03069889608260409

Kokkinos, C. M. (2006). Factor Structure and Psychometric Properties of the Maslach Burnout Inventory-Educators Survey among Elementary and Secondary School Teachers in Cyprus. Stress and Health, 22, 25-33. https://doi.org/10.1002/smi.1079

Kristensen, T. S., Borritz, M., Villadsen, E., \& Christensen, K. B. (2005). The Copenhagen Burnout Inventory: A New Tool for the Assessment of Burnout. Work \& Stress, 19, 192-207. https://doi.org/10.1080/02678370500297720

Kyriacou, C., \& Sutcliffe, J. (1977). Teacher Stress: A Review. Educational Review, 29, 299-306.

Kyriacou, C., \& Sutcliffe, J. (1978b). Teacher Stress: Prevalence, Sources, and Symptoms. British Journal of Educational Psychology, 48, 159-167. https://doi.org/10.1080/0013191770290407

Maslach, C., \& Jackson, E. S. (1986). Maslach Burnout Inventory Manual (2nd ed.). Palo Alto, CA: Consulting Psychologists Press.

Maslach, C., \& Jackson, S. E. (1981). The Maslach Burnout Inventory. Palo Alto, CA: Consulting Psychologists Press, Inc. https://doi.org/10.1037/t05190-000

Mouzoura, E. (2005). Emotional and Occupational Exhaustion Sources and Coping. Linking Individual and Social Sources of Strain. PhD Thesis, Thessaloniki: Aristoteleian University of Thessaloniki.

Mparis, T. (2018). Sources of Occupational Stress in Primary School Teachers. Bachelor Thesis, Thessaloniki: Alexandrion Technological Institute of Thessaloniki.

Okebukola, A. P., \& Jegede, O. J. (1989). Determinants of Occupational Stress among Teachers in Nigeria. Educational Studies, 15, 23-26. https://doi.org/10.1080/0305569890150103

Pines, A. F., \& Aronson, E. (1988). Career Burnout: Causes and Cures. New York: Free Press.

Robson, C. (2011). The Study of the Real World (pp. 114-145). In Stavropoulos, C. (Ed.), Athens, Greece: Gutenberg Publications.

Shirom, A., \& Ezrachi, Y. (2003). On the Discriminant Validity of Burnout, Depression and Anxiety: A Re-Examination of Burnout Measure. Anxiety, Stress \& Coping: An 
International Journal, 16, 83-97. https://doi.org/10.1080/1061580021000057059

Tsigilis, N., Zournatzi, E., \& Koustelios, A. (2011). Burnout among Physical Education Teachers in Primary and Secondary Schools. International Journal of Humanities and Social Science, 1, 53-58.

Van Dick, R., \& Wagner, U. (2001). Stress and Strain in Teaching: A Structural Equation Approach. British Journal of Educational Psychology, 71, 243-259. https://doi.org/10.1348/000709901158505

Vassilopoulos, S. (2012). Burnout and Social Anxiety in Primary School Teachers. Hellenic Journal of Psychology, 9, 18-44. 